\title{
BEHAVIOUR OF STEEL-CONCRETE-STEEL SANDWICH PLATES UNDER DIFFERENT ICE-CONTACT PRESSURE
}

\author{
Jia-Bao Yan ${ }^{1}$, Zhe Wang ${ }^{2}$ and Xuan Wang ${ }^{3, *}$ \\ ${ }^{I}$ Associate Professor, ${ }^{2}$ M.E. Candidate, School of Civil Engineering / Key Laboratory of Coast Civil Structure Safety of Ministry of Education, Tianjin University, Tianjin 300350, P. R. China \\ ${ }^{3}$ Associate Professor, School of Marine Science and Technology, Tianjin University, Tianjin 300072, P. R. China \\ *(Corresponding author: Email: wangx2010water@126.com)
}

\section{A B S T R A C T}

Steel-concrete-steel (SCS) sandwich plate has been developed as the ice-resisting walls in Arctic offshore constructions. This paper investigates the ultimate strength behaviour of SCS sandwich plates under different surface loading area by numerical analysis method. This paper adopted the finite element model that was developed and extensively validated by the test results. Through the 35-case study, the ultimate strength behaviour of the SCS sandwich plate under different surface loading area was investigated. The general load-deflection behaviour of the SCS sandwich plates under different loading area were analysed and summarized. Different failure modes of the SCS sandwich plate under different surface loading area were reported and discussed. The load-transferring mechanism of the SCS sandwich plate under different surface loading area were analysed. Finally, considering the applications of these SCS sandwich plate as the ice-resisting wall in the Arctic offshore constructions, these FE predicted ultimate resistances of the SCS sandwich plates under different surface loading area were compared with the corresponding ice-contact pressure predicted by the design codes. These comparisons confirmed the applicability of developed SCS sandwich plate as the ice-resisting wall in Arctic offshore constructions.
A R T I C L E H I S T O R Y

$\begin{array}{ll}\text { Received: } & 10 \text { September } 2017 \\ \text { Revised: } & 8 \text { July } 2018 \\ \text { Accepted: } & 15 \text { July } 2018\end{array}$

\section{K E Y W O R D S}

Steel-concrete composite structure

Finite element analysis;

Punching shear resistance;

Numerical analysis;

Ice-contact pressure;

steel damage

\section{Introduction}

The explorations of oil and gas in the Arctic region becomes popular recently due to $30 \%$ of the world's undiscovered gas and $13 \%$ of the world's undiscovered oil are stored in this region. With such rich resources, the Arctic will be the essential output region of oil and gas in the future. However, the moving ice sheets in the Arctic ocean that were driven by the wind and current critically threat the Arctic offshore structures used for the oil and gas explorations. Various types of engineering constructions have been proposed and used for the Arctic oil and gas explorations, e.g., artificial island, jacket structure, caisson-retained structure, gravity based conical structure, and floating structures. Marshall et al. [1] and Yan et al. [2] have developed gravity based conical structures (GBCSs) with curved and flat steel-concrete-steel (SCS) type of ice-resisting wall, respectively (see Fig. 1). These GBCSs focused on the applications at Arctic locations with the water depth of 10 100 m. The inclined SCS sandwich plate or shell type of ice-resisting wall would raise the impacting ice sheets and fail them in flexural bending rather than crushing that significantly alleviated the ice-contact pressure acting on the structure. The flat SCS sandwich plate type of ice-resistant wall usually consists of two layers of steel plates and a sandwiched concrete core with the bonding measures (e.g., cohesive material or mechanical shear connectors) to form an integrity. This type of structure shows better buckling resistance and superior ductility over the traditional reinforced concrete (RC) structure. Compared with the traditional RC structure, the transparent advantages of the SCS sandwich plates include saving formwork for concrete casting and labour force for site construction, avoiding the detailing and fabricating of the reinforcements, promising modular construction that improves the construction efficiency, and offering external steel skins as blast- or impact-resistant membranes. This type of structure exhibits versatile potential application in civil and offshore constructions, e.g., shear walls, protective structures, decks in bridges and offshore structures, nuclear walls, containments for oil and liquid natural gas, and ice-resistant walls [1-3].

In the ice-resisting wall system, ice-contact pressure produced by the floating ice becomes the main concern [4]. The pressure at the ice-structure interface could be up to more than $15 \mathrm{MPa}$ on a local area and about $2.5 \mathrm{MPa}$ on a large interacting area [4-7]. Therefore, the structural performances of these ice-resisting walls under the patch loads or large area ice-contact pressure need to be understood for the safety purpose of the Arctic offshore construction. Birdy and Bhula [4] experimentally studied the punching shear behaviour of reinforced concrete plates and shells under concentrated loading. Experimental and analytical works on arch-shaped RC ice-resisting wall under patch loads have been reported by Ellis and Macgregor [7]. Long [8], and Mclean [9]. Mclean et al. [10] have reported the reinforced normal and lightweight concrete

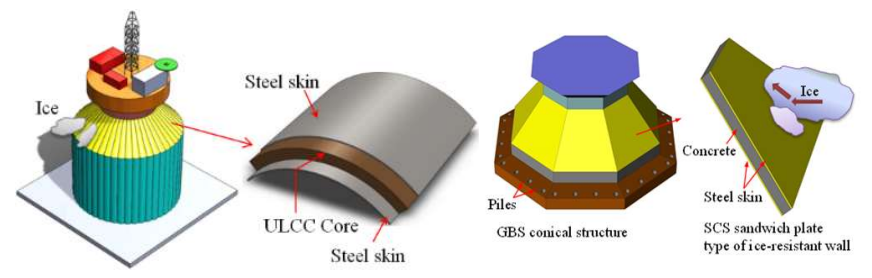

Fig. 1 SCS sandwich plate type of ice-resistant wall in Arctic offshore structure [2]

plate or shell type of ice-resisting walls under patch loads. These literatures showed that previous studies on the ice-resisting walls mainly focused on the normal (or lightweight) reinforced concrete plates or shells. Moreover, all of these studies focused on the structural behaviours of reinforced concrete iceresisting walls under patch loads. Nojiri et al. [11] reported experimental and analytical studies on the steel-concrete composite ice-resisting walls for the Arctic offshore structures. However, this study mainly tested the SCS composite beams that deemed to be different from the SCS sandwich plate structures. Shukry and Goode [12] and Yan et al. [13] investigated punching shear behaviours of the SCS sandwich shells under patch loads. The ultimate strength behaviour of the SCS plates under patch loads have been reported by Sohel et al. [14], Shanmugam et al. [15], and Yan et al. [16-19]. These reported experimental and analytical works mainly focused on the structural behaviours of the SCS sandwich plate (or shell) under patch loads. The information on the SCS sandwich plate under large loading area so far is still quite limited. Therefore, it is of interest and importance to carry out more studies on the structural behaviours of the SCS sandwich plate under different ice-contact loading areas, which would provide more information to understand their structural performances under these different loading scenarios.

Different numerical models have been developed and offer alternative approaches for the analysis on the SCS sandwich structures [15, 20-22], which provided useful and economic means to investigate the structural behaviours of this type of structures. Foundoukos and Chapman [20] developed 2-D FE model for SCS sandwich beam, and this 2-D model limits the simulation of 3D behaviors of the shear connectors in the SCS sandwich structure. Shanmugam et al. [15] developed a simplified 3-D model by introducing anisotropic element that simplified the concrete with inside embedded headed studs. Though this model could globally capture the structural behaviour of the SCS sandwich plates, it could not simulate well the shear failure of the inside connectors and punching shear failure of the concrete core and steel face plates. Great efforts have been made to develop the FE models to simulate the SCS sandwich composite structures with different types of connectors. Yan et al. [21] and Sohel et al. [22] developed the 3-D FE models for SCS sandwich structure through simplifying a pair of overlapped headed studs or interlocked J-hook connectors into two cylindrical studs linked by the nonlinear spring element. However, this model could not accurately simulate the shear-tension interaction strength and damage failure mechanism of steel face plates or connectors. Yan et al. [23] and Yan and Zhang [24] continued this work and developed detailed FE model that offered accurate and detailed simulations on the stud-concrete interactions in 
the SCS sandwich structure. This developed FE model also considered damage in steel and concrete that proved to be capable of simulating the structural behaviour of the SCS sandwich plates and shells [23-4]. Thus, this model offered useful mean to investigate the behaviour of the SCS sandwich plate under larger surface loading area that significantly reduced the costing and time compared with the testing method.

This paper utilized the finite element model (FEM) with detailed simulation on headed shear studs in the SCS sandwich plate that was developed by the authors. In this numerical model, continuum damage plasticity model was used to simulate the damage evolutions in the steel materials. Moreover, concrete damage plasticity model was also used to model concrete core in the SCS sandwich plate. The headed stud connectors in the SCS sandwich plate were detailed simulated, and contact algorithms were used to model different interactions among the concrete core, headed studs, and steel face plates. The accuracy of the developed FEM was validated by nine large scale tests carried out by the authors. With this validated FEM, ultimate strength behaviours of the SCS sandwich plate under different surface loading area were studied. The failure modes, ultimate resistance, and load-transferring mechanism were reported and analysed based on the FE parametric study. The FE predicted resistances of the SCS sandwich plate were also compared with the ISO predicted ice-contact pressure to further confirm its applicability as the iceresisting wall in the Arctic offshore construction.

\section{Tests on steel-concrete-steel sandwich plate}

\subsection{SCS sandwich plate and test setup}

The SCS sandwich plate usually consists of two external steel face plates and a sandwich concrete core as shown in Fig. 2 [16].
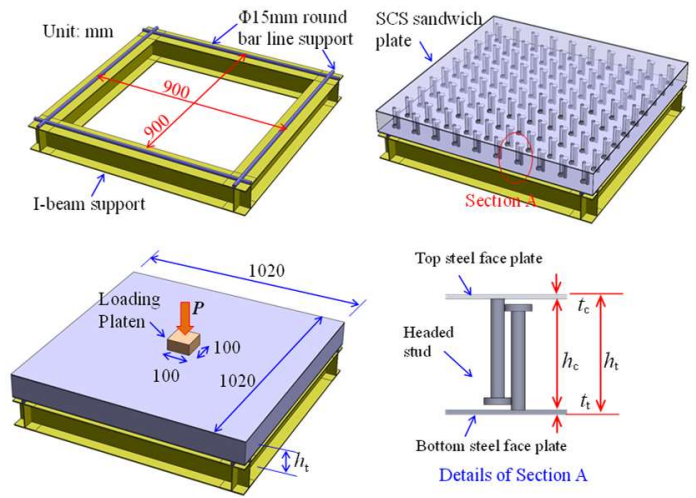

Fig. 2 Details and test setup of SCS sandwich plates [16]

Table 1

Material and geometry details of the tests on SCS sandwich plates

\begin{tabular}{|c|c|c|c|c|c|c|c|c|c|c|}
\hline Specimen & $\begin{array}{c}h_{\mathrm{t}} \\
(\mathrm{mm})\end{array}$ & $\begin{array}{l}t_{\mathrm{t}}=t_{\mathrm{c}} \\
\mathrm{mm}\end{array}$ & $\begin{array}{c}S_{\mathrm{a}} \\
\mathrm{mm}\end{array}$ & $\begin{array}{c}f_{\mathrm{ck}} \\
(\mathrm{MPa})\end{array}$ & $\begin{array}{c}f_{\mathrm{t}} \\
(\mathrm{MPa})\end{array}$ & $\begin{array}{l}\text { Stud } \\
d \times h_{s} \\
\mathrm{~mm}^{2}\end{array}$ & $\begin{array}{c}E_{s} \\
(\mathrm{GPa})\end{array}$ & $\begin{array}{c}f_{\mathrm{y}} \\
(\mathrm{MPa})\end{array}$ & $\begin{array}{c}f_{\mathrm{u}} \\
(\mathrm{MPa})\end{array}$ & $\begin{array}{c}E_{\text {sh }} \\
(\mathrm{GPa})\end{array}$ \\
\hline SP1 & 112.0 & 4 & 100 & 65.1 & 4.1 & $13 \times 100$ & 202 & 317.8 & 472.0 & 199 \\
\hline SP2 & 107.7 & 4 & 150 & 65.1 & 4.1 & $13 \times 100$ & 202 & 317.8 & 472.0 & 199 \\
\hline SP3 & 110.9 & 4 & 100 & 46.0 & 2.9 & $13 \times 100$ & 202 & 317.8 & 472.0 & 199 \\
\hline SP4 & 111.8 & 4 & 100 & 54.7 & 3.4 & $13 \times 100$ & 202 & 317.8 & 472.0 & 199 \\
\hline SP5 & 117.5 & 6 & 100 & 65.1 & 4.1 & $13 \times 100$ & 204 & 435.0 & 538.7 & 199 \\
\hline SP6 & 120.2 & 8 & 100 & 65.1 & 4.1 & $13 \times 100$ & 200 & 330.8 & 486.0 & 199 \\
\hline SP7 & 110.9 & 4 & 100 & 62.7 & 5.1 & $13 \times 100$ & 202 & 317.8 & 472.0 & 199 \\
\hline SP8 & 73.8 & 4 & 100 & 68.4 & 4.2 & $13 \times 70$ & 202 & 317.8 & 472.0 & 198 \\
\hline SP9 & 135.0 & 4 & 100 & 68.4 & 4.2 & $13 \times 100$ & 202 & 317.8 & 472.0 & 199 \\
\hline
\end{tabular}

Table 1

Continued

\begin{tabular}{|c|c|c|c|c|c|c|c|c|c|}
\hline Specimen & $\begin{array}{c}E_{s h} \\
(\mathrm{GPa}) \\
\end{array}$ & $\begin{array}{c}\sigma_{\mathrm{y}} \\
(\mathrm{MPa})\end{array}$ & $\begin{array}{c}\sigma_{\mathrm{y}} \\
(\mathrm{MPa}) \\
\end{array}$ & $\begin{array}{c}P_{1} \\
(\mathrm{kN})\end{array}$ & $\begin{array}{c}P_{2} \\
\mathrm{kN} \\
\end{array}$ & $\begin{array}{l}P_{1, F} \\
(\mathrm{kN})\end{array}$ & $\frac{P_{1, F}}{P_{1}}$ & $\begin{array}{l}P_{2, F} \\
(\mathrm{kN})\end{array}$ & $\frac{P_{2, F}}{P_{2}}$ \\
\hline SP1 & 199 & 418.5 & 505.5 & 482.8 & 618.8 & 458.8 & 0.95 & 609.0 & 0.98 \\
\hline SP2 & 199 & 418.5 & 505.5 & 288.0 & 518.8 & 264.0 & 0.92 & 441.7 & 0.85 \\
\hline SP3 & 199 & 418.5 & 505.5 & 427.3 & 547.9 & 406.6 & 0.95 & 607.8 & 1.11 \\
\hline SP4 & 199 & 418.5 & 505.5 & 464.6 & 520.9 & 435.0 & 0.94 & 613.7 & 1.18 \\
\hline SP5 & 199 & 418.5 & 505.5 & 624.5 & 859.2 & 670.0 & 1.07 & 776.9 & 0.90 \\
\hline SP6 & 199 & 418.5 & 505.5 & 811.6 & 1067.5 & 771.0 & 0.95 & 1062.8 & 1.00 \\
\hline SP7 & 199 & 418.5 & 505.5 & 512.6 & 638.2 & 459.8 & 0.90 & 604.5 & 0.95 \\
\hline SP8 & 198 & 417.0 & 495.3 & 284.5 & 529.9 & 365.4 & 1.28 & 545.9 & 1.03 \\
\hline \multirow[t]{3}{*}{ SP9 } & 199 & 418.5 & 505.5 & 540.7 & 583.4 & 519.7 & 0.96 & 607.0 & 1.04 \\
\hline & & & & & & $u$ & 0.99 & & 1.00 \\
\hline & & & & & & $\mathrm{COV}$ & 0.12 & & 0.10 \\
\hline
\end{tabular}

$h_{\mathrm{t}}$ denotes total depth of the SCS sandwich plate; $t_{\mathrm{t}}, t_{\mathrm{c}}$ denote thickness of tension and compression steel face plates, respectively; $S_{\mathrm{a}}$ denote spacing of the studs; $f_{\mathrm{t}}, f_{\mathrm{ck}}$ denote tensile an compressive strength of the concrete core, respectively; $d, h_{\mathrm{s}} \sigma_{\mathrm{y}}, \sigma_{\mathrm{y}}$ denote diameter, height, yield and ultimate strength of the stud, respectively; $E_{s h}, f_{\mathrm{y}}, f_{\mathrm{u}}$ denote Young's modulus, yield and ultimate strength of the steel plate, respectively; $P_{1, \mathrm{~F}}$ and $P_{2, \mathrm{~F}}$ denotes first and second peak resistance by FEA, respectively

Headed studs were firstly welded to the two external steel faceplates, and after casting of the concrete they were anchored to the concrete core and bond these three layers of materials as an integrity. Nine specimens in total were prepared and tested under patch loads [16]. All the specimens measuring $1020 \times 1020 \mathrm{~mm} 2$ (length by width) adopted the ultra-lightweight cement composite (ULCC) as the core material. More material and geometric details of the SCS sandwich plates are given in Table 1. As shown in Fig. 2(b), all the specimens were applied by the concentrated loads at the center of top steel face plate through a steel cube measuring $100 \times 100 \times 100 \mathrm{~mm} 3$. The deflections of the plates at middle span were measured by the Linear Varying Displacement Transducers (LVDTs).

\subsection{Materials}

Ultra-lightweight cement composite (ULCC) with a 28-day compressive strength about $60 \mathrm{MPa}$ and a density of $1450 \mathrm{~kg} / \mathrm{m} 3$ was adopted as the core materials in the SCS sandwich plate that aims to deliver a lightweight structural solution. The detailed information on the ULCC has been extensively reported by Chia et al. [25], Yan et al. [26], and Wang et al. [27]. Fig. 3(a) and (b), respectively, show the representative compressive and tensile stress-strain curves of the ULCC that were obtained from the material tests. The tensile and compressive strengths of the ULCC for each specimen were listed in Table 1. 


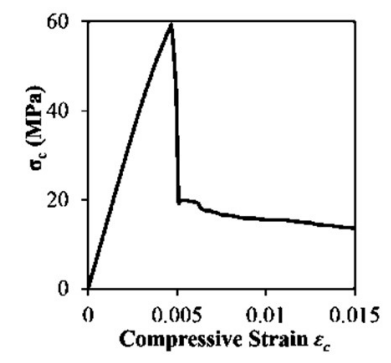

(a) Compressive stress-strain curve

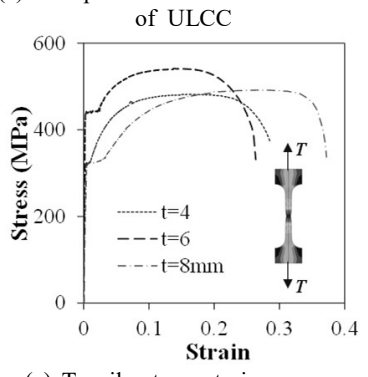

(c) Tensile stress-strain curves of steel plates

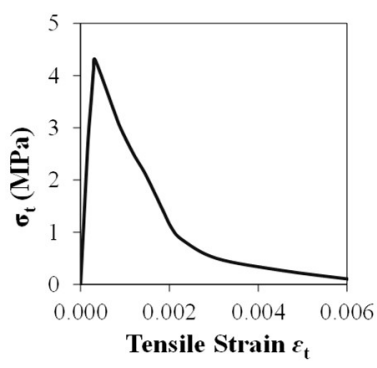

(b) Tensile stress-strain curve of ULCC

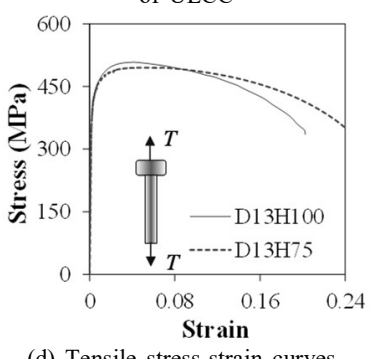

(d) Tensile stress-strain curves

of headed studs

Fig. 3 Stress-strain curves of ULCC, headed studs and steel skin plates [16]

Mild steel plates with different thicknesses of 4,6 , and $8 \mathrm{~mm}$ were used to fabricate the SCS sandwich plate. Fig. 3(c) depicts the tensile engineering stress-strain curves of these steel face plates [16]. Headed studs with height of $75 \mathrm{~mm}$ and $100 \mathrm{~mm}$ were used in this test program. The tensile engineering stress-strain curves of these two types of headed studs are shown in Fig. 3(d) [16]. Table 1 lists all the mechanical properties of the ULCC and the steel materials involved in this test program.

\section{Finite element modelling}

\subsection{General}

General finite element code ABAQUS/CAE was used for the FE modelling of the SCS sandwich plate with the headed shear studs [26]. ABAQUS/Explicit type of solver was chosen to overcome the convergence problem during the nonlinear analysis of the SCS sandwich plate.

\subsection{Finite element model}

The finite element model (FEM) developed by Yan et al. [23-4] provides detailed modelling on the headed studs in the SCS sandwich plate to achieve a successful stud-concrete interacting simulation. Fig. 4 shows the FEM for SCS sandwich plate as proposed by Yan et al. [24]. One quarter of the full size specimen was built in this FEM that considered the symmetric geometry and loading pattern (see Fig. 4). Hundreds of headed studs on both top and bottom steel plate in SCS sandwich plate were detailed modelled as shown in Fig. 4. The holes in the concrete core were also reserved for these headed studs. In order to facilitate the FE modelling, the square section of headed studs was used to replace the circular section through using equivalent cross sectional area and height. This simplification was proved be efficient in the FE model building and also offered satisfactory simulations on the behaviour of the SCS sandwich plate [23-24].

The FEM adopted three-dimensional eight-node continuum elements (C3D8R) in ABAQUS element library to simulate the different components in the SCS sandwich plate, e.g., headed stud, steel plate, and concrete core. The C3D8R element had eight nodes with three translation degrees of freedom on each node and one integration point.

In order to make a balance of computing efficiency and accuracy, different mesh sizes in the FEM were used. The mesh size of the C3D8R element for the headed stud is $5 \times 5 \times 5 \mathrm{~mm} 3$; the mesh sizes of the elements in the steel face plate near and far away from the headed studs are $5 \times 5 \times 2 \mathrm{~mm} 3$ and $10 \times 10 \times 2 \mathrm{~mm} 3$, respectively; the mesh sizes of the elements in the concrete core near and far away from the headed studs are $5 \times 5 \times 10 \mathrm{~mm} 3$ and $5 \times 10 \times 10 \mathrm{~mm} 3$, respectively. Taking the specimen SP1 for example, there are 10874, 31020, and 10874 elements for the bottom steel plate, concrete core, and top steel plate, respectively.
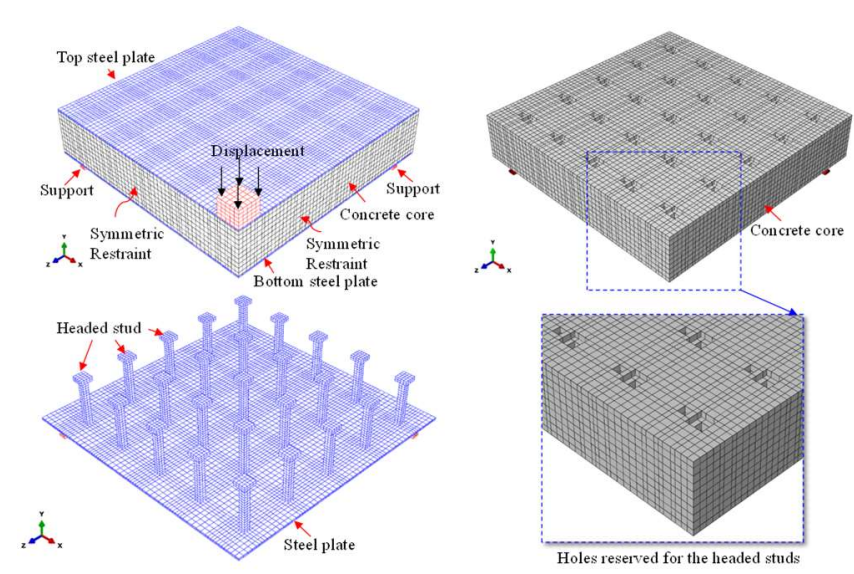

Fig. 4 FE model for SCS sandwich plate

\subsection{Loadings and interactions}

Since the FEM only built one quarter of the SCS sandwich plate, symmetric restraints have been applied on the surfaces of the sections along the centreline as shown in Fig. 4. Displacement controlled type of loading was applied on the centre of the top steel face plate through a steel cube measuring $100 \mathrm{~mm}$ in width. The round bar type of line support was also modelled and hard contact was defined to simulate its interaction with the SCS sandwich plate.

Different interacting pairs among different components (e.g., interaction between studs and concrete core, interaction between steel plates and concrete core, and interaction between loading platen and top steel face plates) adopted surface-to-surface contact algorithm in the FEM. Hard contact algorithm and Coulomb friction model were used to define the contact algorithms in the normal direction and tangent direction to the contact surface, respectively. The hard contact algorithm allows transferring the contact pressure of the surface under compression, and permits separation without transferring pressure once the two interacting surfaces are under tension. In Coulomb friction algorithm, a friction coefficient was used to simulating the friction forces at the interacting surfaces. In this paper, a value of 0.4 was chosen that has been used in this developed FEM for the SCS sandwich plates [24].

\subsection{Material model of concrete}

The FEM adopted the concrete damage plasticity model (CDPM) in ABAQUS to simulate the mechanical properties of the concrete core. In CDPM model, isotropic tensile and compressive plasticity with isotropic damage was used to describe the inelastic mechanical behaviours of the concrete [28]. The yield function proposed by Lublinear et al. [29] and modified by Lee and Fenves [30] was used to define the evolution of the strength of the concrete under compression and tension. The non-associated potential flow rule and isotropic damage were followed in the CDPM [28].

The CDPM model in ABAQUS used the uniaxial tensile and compressive stress-strain curves to define the constitutive model of the concrete. For the ULCC used in this study the experimental tensile and compressive stress-strain curves were used to calibrate the CDPM model [24].

These uniaxial tensile and compressive engineering stress-strain curves have to be converted to the inelastic strain versus stress curves as specified in ABAQUS material library. In the CDPM, the consideration on the strainsoftening of the concrete core was realized through introducing the damage coefficient. Thus, in the CDPM model, the compressive and tensile damage coefficient versus inelastic strain curves were used to specify this strainsoftening, i.e., $D_{c}\left(\right.$ or $\left.D_{t}\right) \sim \varepsilon_{c}^{I n}\left(\right.$ or $\left.\varepsilon_{t}^{I n}\right)$ curves as defined,

$$
\begin{gathered}
\varepsilon_{c}^{p l}=\varepsilon_{c}^{I n}-\frac{D_{c}}{\left(1-D_{c}\right)} \frac{\sigma_{c}}{E_{0}} \\
\varepsilon_{t}^{p l}=\varepsilon_{t}^{I n}-\frac{D_{t}}{\left(1-D_{t}\right)} \frac{\sigma_{t}}{E_{0}}
\end{gathered}
$$

where, $\varepsilon_{t}^{p l}$ and $\varepsilon_{c}^{p l}$ denote true tensile or compressive plastic strain of the concrete, respectively; $\varepsilon_{t}^{I n}$ and $\varepsilon_{c}^{I n}$ denote inelastic tensile or compressive strain of the concrete, respectively; $D_{c}$ and $D_{t}$ denote the compressive and tensile damage ratio, respectively. The $D_{c}\left(\operatorname{or} D_{t}\right)$ can be determined by the following proposed functions as proposed by Wang and Chen [31]

$$
\begin{aligned}
& D_{c}=A_{c} e^{-\bar{\varepsilon}_{c}^{I n} / t_{c}}+B_{c} \\
& D_{t}=A_{t} e^{-\bar{\varepsilon}_{t}^{I n} / t_{t}}+B_{t}
\end{aligned}
$$


where $\bar{\varepsilon}_{c}^{I n}$ and $\bar{\varepsilon}_{t}^{I n}$ refer to the inelastic compressive and tensile strain against the maximum strain in the stress-strain curves, respectively; $t_{c}$ and $t_{t}$ are a constant empirical values; $A_{c}=\frac{1}{e^{-1 / t_{c-1}}} ; B_{c}=-\frac{1}{e^{-1 / t_{c-1}}} ; A_{t}=\frac{1}{e^{-1 / t} t-1}$; $B_{t}=-\frac{1}{e^{-1 / t} t-1}$.

Finally, Fig. 5(a) and (b) show the determined compressive and tensile damage ratio versus inelastic strain curves for CDPM, respectively.

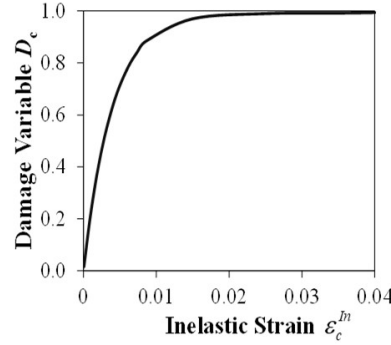

(a) Compression damage variables for ULCC

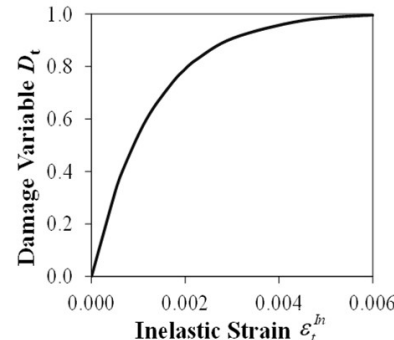

(b) Tension damage variables for UL $\mathrm{CC}$
Fig. 5 Definitions of the stress-strain curves and damage variables for CDPM

The other plasticity parameters including flow potential eccentricity of 0.1 , ratio of the biaxial/uniaxial compressive strength ratio of 1.16 , and the dilation angles of $36^{\circ}$ were chosen for the CDPM in the FEM developed in this paper.

\subsection{Material model of steel and connector}

The proposed FEM [24] adopted the continuum damage model (CDM) for the steel face plates and headed studs. The tensile stress-strain curves that were obtained from the uniaxial tensile tests as shown in Figs. 3(c) and (d) were used in this FE modelling. From these test data, the elastic modulus Es and Poisson's ratio $v$ were determined as $200 \mathrm{GPa}$ and 0.3 , respectively.

In the definition of the CDM, the damage initiation criterions, damage evolution laws, and true stress-strain curves of the steel materials were required. This paper follows the methods proposed by Yan et al. [23-4] and detailed information could be found in Refs. [23, 24].

\subsection{Validations of the finite element model}

The comparisons between the test results and FE analysis proved that the developed FE model could provide satisfactory FE simulations on the loaddeflection behaviours, deformation behaviour, the first and second peak resistances of the SCS sandwich plate, and failure modes of the SCS sandwich plate that includes the punching shear in the concrete core and steel face plates [24]. Table 1 compares the FE predicted ultimate resistances with those experimental values. It can be seen that the average test-to-prediction ratio (nine tests) for the first and second peak resistance are 0.99 and 1.00 with corresponding of coefficient of variation for the test-to-prediction ratios of 0.12 and 0.10 , respectively.

Thus, this validated FE model could be used to investigate behaviour of the SCS sandwich plate under different loading area.

\section{Ultimate strength behaviour of SCS sandwich plate under different loading area}

\subsection{FE parametric studies on SCS sandwich plate under different loading area}

Ultimate strength behaviour of the SCS sandwich plate under different loading area was carried out by the validated FEM.
Table 2

Details and results of the FEA cases

\begin{tabular}{lccccl}
\hline FE Case & $\begin{array}{c}L \mathrm{a} \\
(\mathrm{m})\end{array}$ & $\begin{array}{c}A \\
\left(\mathrm{~m}^{2}\right)\end{array}$ & $\begin{array}{c}P_{\max } \\
(\mathrm{kN})\end{array}$ & $\begin{array}{c}p \\
(\mathrm{MPa})\end{array}$ & Failure mode \\
\hline SP1A0 & 0.10 & 0.01 & 482.8 & 48.3 & PSC \\
SP1A1 & 0.20 & 0.04 & 757.2 & 18.9 & FLC \\
SP1A2 & 0.45 & 0.20 & 977.7 & 4.8 & FLC \\
SP1A3 & 0.64 & 0.40 & 1365.9 & 3.4 & FLC \\
SP1A4 & 0.90 & 0.81 & 2106.0 & 2.6 & FLC \\
\hline SP3A0 & 0.10 & 0.01 & 464.6 & 46.5 & PSC \\
SP3A1 & 0.20 & 0.04 & 730.0 & 18.2 & FLC \\
SP3A2 & 0.45 & 0.20 & 956.8 & 4.7 & FLC \\
SP3A3 & 0.64 & 0.40 & 1350.0 & 3.3 & FLC \\
SP3A4 & 0.90 & 0.81 & 1944.0 & 2.4 & FLC \\
\hline SP5A0 & 0.10 & 0.01 & 624.5 & 62.5 & PSC \\
SP5A1 & 0.20 & 0.04 & 742.6 & 18.6 & FLC \\
SP5A2 & 0.45 & 0.20 & 967.6 & 4.8 & FLC \\
SP5A3 & 0.64 & 0.40 & 1356.3 & 3.4 & FLC \\
SP5A4 & 0.90 & 0.81 & 1944.0 & 2.4 & FLC \\
\hline SP6A0 & 0.10 & 0.01 & 811.6 & 81.2 & PSC \\
SP6A1 & 0.20 & 0.04 & 784.9 & 19.6 & FLC \\
SP6A2 & 0.45 & 0.20 & 1105.9 & 5.5 & FLC \\
SP6A3 & 0.64 & 0.40 & 1469.2 & 3.6 & FLC \\
SP6A4 & 0.90 & 0.81 & 2268.0 & 2.8 & FLC \\
\hline
\end{tabular}

Table 2

Continued

\begin{tabular}{lccccl}
\hline FE case & $\begin{array}{c}L \mathrm{a} \\
(\mathrm{m})\end{array}$ & $\begin{array}{c}\mathrm{A} \\
(\mathrm{m} 2)\end{array}$ & $\begin{array}{c}P_{\max } \\
(\mathrm{kN})\end{array}$ & $\begin{array}{c}p \\
(\mathrm{MPa})\end{array}$ & Failure mode \\
\hline SP7A0 & 0.10 & 0.01 & 512.6 & 51.3 & PSC \\
SP7A1 & 0.20 & 0.04 & 1179.0 & 29.5 & FLC \\
SP7A2 & 0.45 & 0.20 & 1372.5 & 6.8 & FLC \\
SP7A3 & 0.64 & 0.40 & 2192.9 & 5.4 & FLC \\
SP7A4 & 0.90 & 0.81 & 2268.0 & 2.8 & FLC \\
\hline SP9A0 & 0.10 & 0.01 & 284.5 & 28.5 & PSC \\
SP9A1 & 0.20 & 0.04 & 488.4 & 12.2 & FLC \\
SP9A2 & 0.45 & 0.20 & 648.0 & 3.2 & FLC \\
SP9A3 & 0.64 & 0.40 & 870.2 & 2.2 & FLC \\
SP9A4 & 0.90 & 0.81 & 1458.0 & 1.8 & FLC \\
\hline SP10A0 & 0.10 & 0.01 & 540.7 & 54.1 & PSC \\
SP10A1 & 0.20 & 0.04 & 745.0 & 18.6 & FLC \\
SP10A2 & 0.45 & 0.20 & 1118.7 & 5.5 & FLC \\
SP10A3 & 0.64 & 0.40 & 1229.0 & 3.0 & FLC \\
SP10A4 & 0.90 & 0.81 & 2430.0 & 3.0 & FLC \\
\hline
\end{tabular}

$L$ a denotes length of the square patch area; $A$ denotes area of the patch loads; $P_{\max }$, and $p$ denote ultimate resistance and pressure, respectively; PSC denotes punching shear failure of the concrete core; FLC denotes flexural failure due to connectors; SP1 $\overline{\mathrm{A} 0}$ Loading area size A0

Different surface loading area was considered that simulated the different ice-interacting area on the Arctic offshore structures. Eight specimens as reported in the experimental program, i.e., SP1, SP4 7, and SP9 10 were chosen as the controlling cases in this study. For each specimen, including the test under $100 \times 100 \mathrm{~mm} 2$ patch loading, four more analyses for each specimen under different loading area A (in $\mathrm{mm} 2$ ) with length $\mathrm{La}(\mathrm{mm})$ measuring 200 , 450, 675, and $900 \mathrm{~mm}$ were carried out. Thus, taking specimen SP1 for example, the FE analyses (FEAs) SP1A0 A4 denotes the SCS sandwich plate was applied to square loading area measuring $100 \times 100,200 \times 200,400 \times 400$, $675 \times 675$, and $900 \times 900 \mathrm{~mm} 2$, respectively. Thus, including the seven tests on the SCS sandwich plates, there are totally 35 results. Fig. 6 shows the details of FEA cases on the SCS sandwich plate under different loading area, and Table 2 lists details of the different FEA cases in this parametric study. 

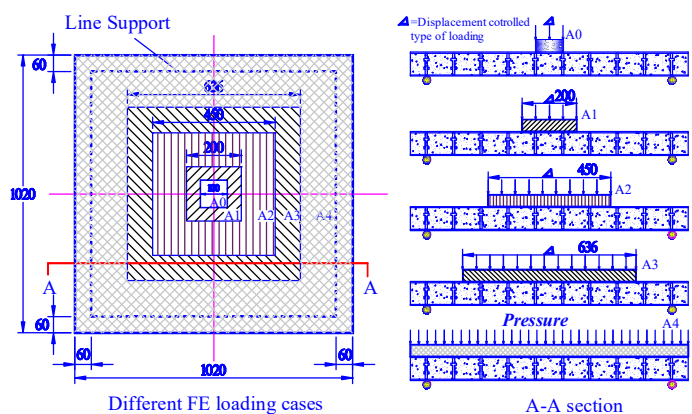

Fig. 6 Illustration on different loading cases in FE parametric study

\subsection{Finite element analysis results and discussions}

\subsubsection{General behavior}

Fig. 7 (a) (h) plots the resultant force versus central deflection curves of the SCS sandwich plate under different loading area. As reflected in Fig. 7, the load-deflection curves of the SCS sandwich plate can be categorized into three types. Fig. 8 shows the generalized load-deflection curves of the SCS sandwich plate under different loading area. The firs type is for the SCS sandwich plate under patch loading of $100 \times 100 \mathrm{~mm} 2$. This type of load-deflection curves exhibited two peak resistances. From the experimental studies on SCS sandwich plate under concentrated loading by Yan et al. [16], the first peak resistance was achieved when the concrete core was punched through, and the second peak resistance of the SCS sandwich plate occurred when the region of top steel skin near the patch loading was punched through. The second type of the loaddeflection curves occurred to the specimens under medium size of surface pressure. As reflected in Fig. 7, the reaction forces of the SCS sandwich plate increases with the applied displacement type of surface loading until the concrete core was punching through or shear failure mode occurred to the support. The third type of load-deflection curves occurred to the specimens under full surface pressure. As reflected in Fig. $7 \sim 8$ the specimens belonged to this type exhibit ductile load-deflection behaviour. These figures show that the load carrying capacity of specimens firstly increased linearly with their central deflections. After the elastic limit, the load carrying capacity of the specimens continue increasing with gradually decreased stiffness. And the specimens exhibit certain degree of ductility with a plateau in the load-defection curves. Finally, these SCS sandwich specimens failed in excessive deflection.

From Fig. 7 and 8, it can be concluded that as the loading area increases the load-deflection behaviours of the SCS sandwich plate changes from the brittle behaviour to the ductile behaviour. Only the SCS sandwich plate under loading area of $100 \mathrm{~mm}$ (i.e., $\mathrm{La} / \mathrm{L}$ ratio equals to about 0.98 ) exhibited two peak resistances. Except the FE analysis cases under full surface pressure and patch loading of $100 \times 100 \mathrm{~mm} 2$, the rest specimens all exhibited one peak resistance. The FE analysis cases under full surface pressure exhibit ductile behaviour. These differences in the load-deflection behaviours implied that the failure mode at final stage changes as the surface loading area increases.

\subsubsection{Ultimate resistances and failure modes}

From these load-deflection curves in Fig. 7, the ultimate resistance of the SCS sandwich plate can be easily determined. The ultimate resistance and pressure for different FEA cases are listed in Table 2. With these ultimate resistances, the ultimate pressure for these loading cases could be obtained, and the ultimate pressure versus La (length of the square loading area) relationshipare plotted in Fig. 9. From these table and figures, it can be found that the ultimate resisting pressure of the SCS sandwich plate decreases dramatically as the length of the square interacting area increases from $0.1 \mathrm{~m}$ to $0.45 \mathrm{~m}$. For the seven SCS sandwich plates with different parameter, the ultimate resisting pressure of the specimens under $0.2 \mathrm{~m} 2$ surface pressure area was averagely reduced to about $10 \%$ of the value for the specimen under $0.01 \mathrm{~m} 2$ surface pressure loading area. However, this decreasing rate of the ultimate resisting

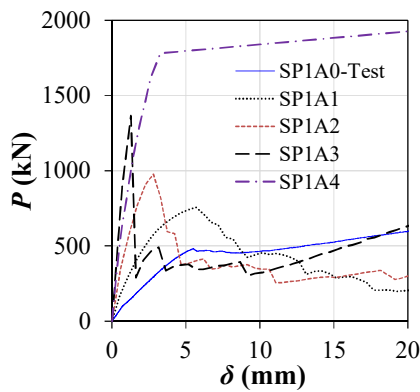

(a)

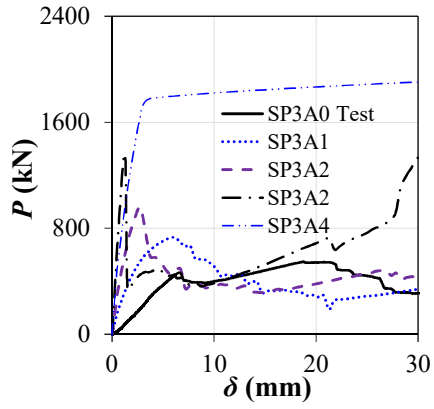

(b)

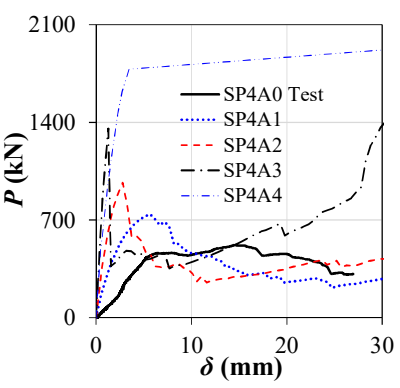

(c)

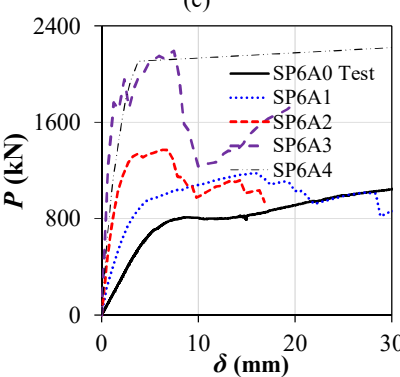

(e)

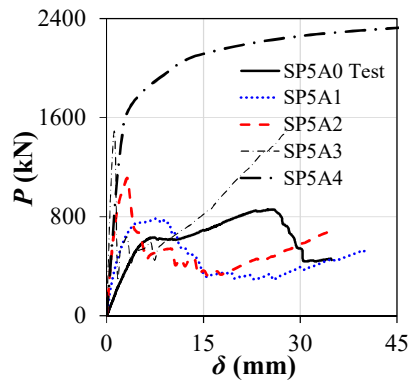

(d)

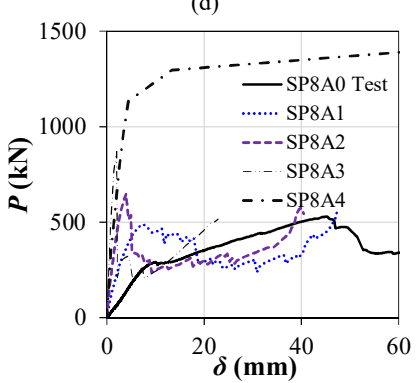

(f)

Fig. 7 Load-central deflection curves of SCS sandwich plate under different loading area

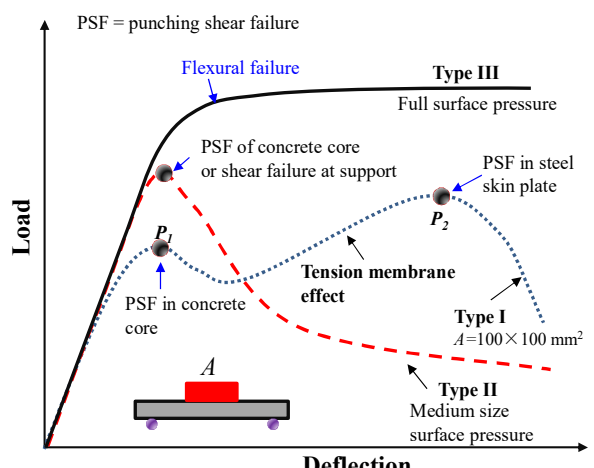

Fig. 8 Illustration on generalized load-deflection curves of SCS sandwich plate under different loading area

pressure acting on the specimen tends to slow down as the square surface loading area increases from $0.2 \mathrm{~m} 2$ to $0.81 \mathrm{~m} 2$. As the surface loading area increases about four times from $0.2 \mathrm{~m} 2$ to $0.81 \mathrm{~m} 2$, the ultimate resisting pressure of the SCS sandwich plate was only reduced by about $50 \%$.

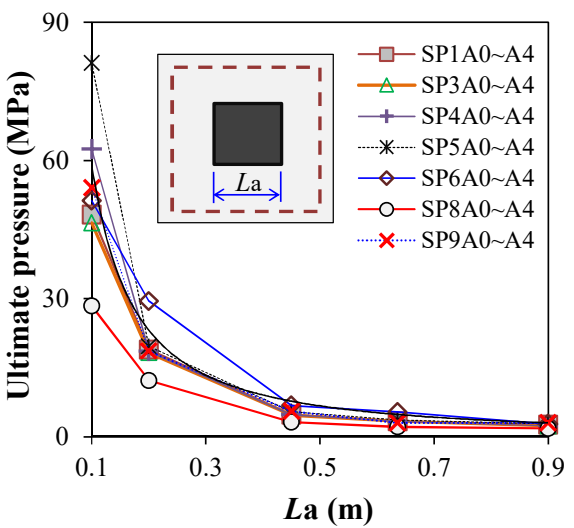

Fig. 9 Ultimate pressure versus loading area relationship for different specimens loading area

Based on these 35 FEA cases, two main types of failure modes were observed, i.e., punching shear failure in the core material and flexural failure mode due to failure of the connectors. Fig. 10(a) depicts the representative contour of the plastic strain distribution in specimen SP1A0. This figure shows a clearly developed punching cone due to large shear deformation. Meanwhile, no plastic strain was observed in both top and bottom steel face plates. Moreover, as reflected in the load-deflection curves in Fig. 7, there are sharp reductions in the load carrying capacity of the SCS sandwich plate. These observations implied that punching shear failure occurred to the core material in specimen SP1A0. This type of failure of occurred to specimens under $100 \times 100 \mathrm{~mm} 2$ square patch loads. 


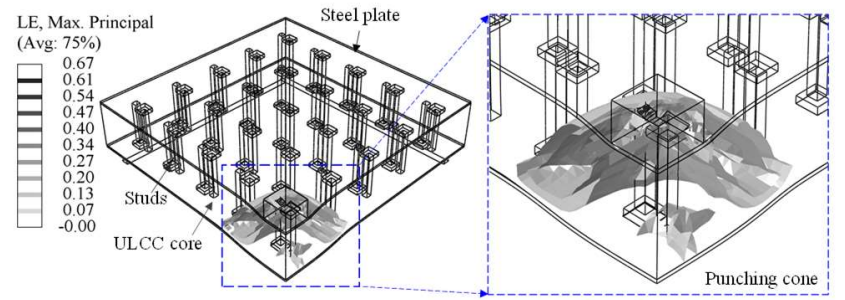

(a) Punching shear failure in the ULCC core predicted by FEA

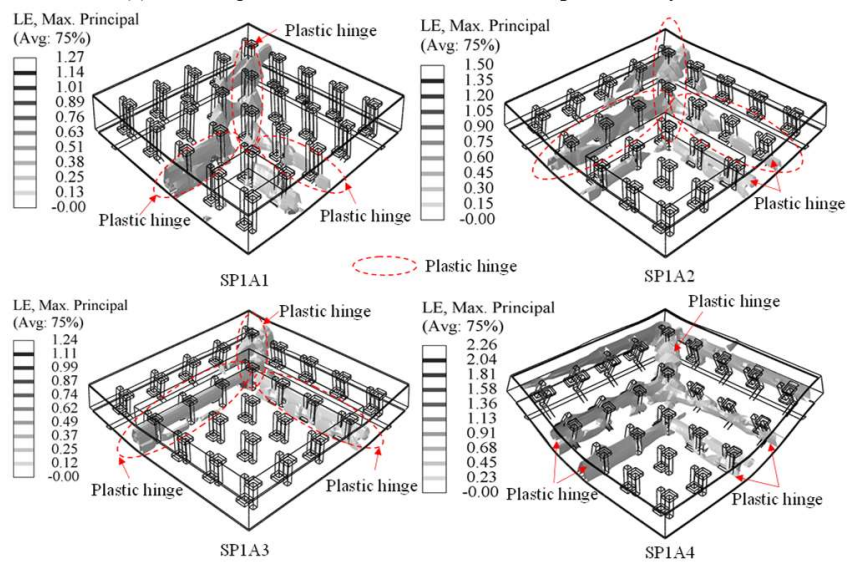

(b) Flexural failure for the plates with the developed plastic yielding lines

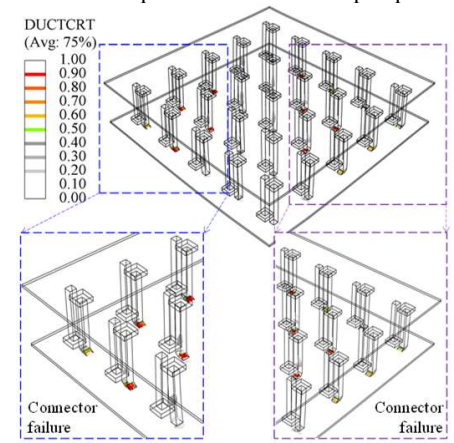

(c) Connector failure type of flexure failure mode

Fig. 10 Different failure modes of the SCS sandwich plate

Fig. 10(b) plots the representative contour of the plastic strain in the specimen SP1A1 4. This figure shows that typical plastic hinges were observed along the edges of the square patch loads and in the diagonal direction that connects the corner of the specimen and corner of the square loading area. These plastic hinges were mainly produced by the excessive rotation. No punching cones were observed in these four specimens. These observations implied that the section along these yielding lines failed in flexural bending. This supports the statement that the specimens under larger loading area failed in flexural bending rather than punching shear mode. There were three types of flexural failure modes that may occur to the SCS sandwich plates, i.e., yielding of the steel face plates, failure of the connectors, or combinations of these two modes. The FEA analyses show that most of the FEA cases failed in the mode due to failure of the connectors as shown in Fig. 10(c). The ultimate resisting force and pressure of each FEA case as well as corresponding failure mode are listed in Table 2.

\subsubsection{Load-transferring mechanism}

As the surface loading area is small (e.g., patch loading), the applied load is taken by the SCS sandwich plate and transferred to the support in two directions as shown in Fig. 11(a). During this stage, the SCS sandwich plate behaves elastically with the top and bottom steel skin plate under compression and tension, respectively (see Fig. 11(a)). Considering the strain compatibility between the concrete core and steel face plates, the concrete core tends to fail prior to the failure of the steel skin plate. Thus, as shown in Fig. 11(b), punching shear failure of the concrete core tends to occur that corresponds to the first peak resistance on the load-deflection curves (see Fig. 9). After a cone of concrete in the SCS sandwich plate is punched through, the top steel skin plate would continue taking the applied load and transferring the load to the rest undamaged portion of the SCS sandwich plate through the tension membrane effect (see Fig. 11(b)). And a new balanced larger critical perimeter than the size of the punched concrete cone will be formed. Thus, as shown in Fig. 11(b), the top steel skin plate within the scope of the punched concrete cone will be under tension due to the tension membrane effect whilst the top steel skin plate out of this scope is under compression. The bottom steel skin plate is still under tension due to bending or pushing down effect by the punched concrete cone. For the SCS sandwich plate under medium size of surface loading area, punching shear failure may occur at the support or in the vicinity of the loading area as shown in Fig. 11(c). Once the surface pressure was applied on the top steel skin plate, all the SCS sandwich plats fail in flexural mode. As illustrated in Fig. 11(c) and Fig. 10, it can be found that the plastic "yielding lines" were formed. This observation was also consistent with the experimental results reported by Sohel et al. [14], Yan et al. [17], and Shanmugam et al. [32]. The applied surface pressure was transferred in two ways along the sandwich plate.

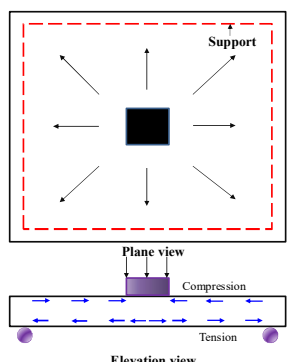

(a) Before punching shear in concrete core of SCS sandwich plate under patch

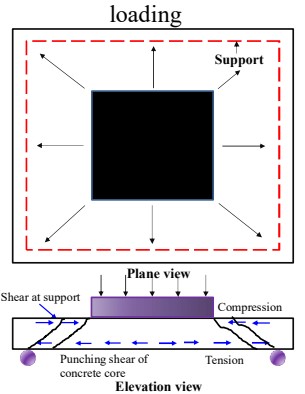

(c) Punching shear failure of concrete core and support for medium surface loa ding area

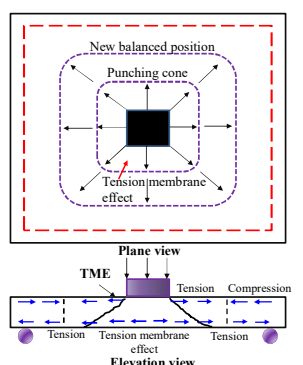

(b) After punching shear of concrete core of SCS sandwich plate under patch loading

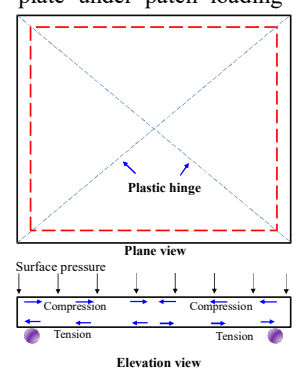

(d) Flexural failure for SCS under full surface pressure
Fig. 11 Load-transferring mechanism of SCS sandwich plate under different surface loading area

4.2.4. Comparisons of resistances of SCS sandwich plates under different surface loading area with the ice-contact pressure by ISO code

Since the developed SCS sandwich plate was developed as the ice-resisting wall in Arctic offshore structure, its ultimate resistance under different surface ice-contact pressure becomes the main concern. The ice-contact pressure, IP, with varying interaction surface, $\mathrm{A}$, which acts on the Arctic offshore structure may be calculated by ISO/FDIS 19906 [32] as follows:

$$
I P=\left\{\begin{array}{c}
7.4 A^{-0.7} A \leq 10 m^{2} \\
1.48 A>10 m^{2}
\end{array}\right.
$$

where, IP is in MPa; $\mathrm{A}$ is in $\mathrm{m} 2$.

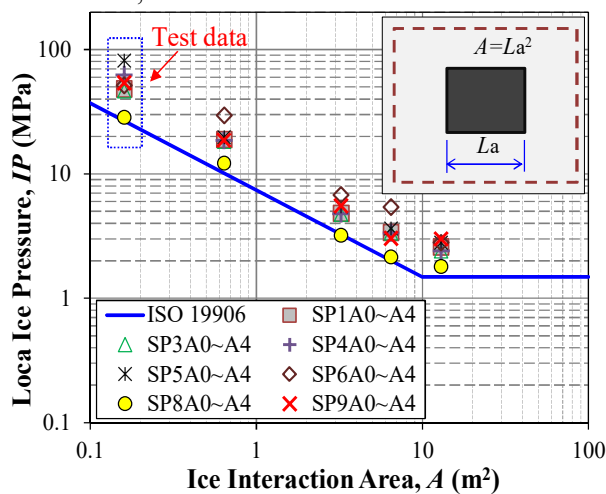

Fig. 12 Comparisons of the resistance of the SCS sandwich plates with the differe nt size of surface ice-contact pressure

Considering that all the tested specimens were $1 / 4$ scaled, the ice-structure interacting area needs to be determined accordingly. Fig. 12 compares the ultimate resisting pressure of the 35 results (seven tests and 28 FEA) with the calculated ice-contact pressure by Eq. 3. This figure shows that the ISO criteria with a reasonable safety factor could be satisfied for all the developed SCS 
sandwich plate type of ice-resisting wall under different surface ice contacting area. These comparisons with the ISO ice-contact pressure further confirms that the developed SCS sandwich plate system could be used to resist the ice-contact pressure in the Arctic offshore constructions.

\section{Conclusions}

This paper utilized the developed a finite element model (FEM) to investigate the ultimate strength behaviour of steel-concrete-steel sandwich plates under different surface loading area. The numerical studies provided valuable information on the ultimate strength behaviour of the SCS sandwich plate under different surface loading area. In addition, the ultimate resistances of the SCS sandwich plate under different loading area were checked by the icecontact pressure, which was the main concern for the SCS sandwich plate type of ice-resisting wall. Based on these FE investigations, the following observations and conclusions are drawn;

(1) The CDPM and CDM were successfully applied in the FE analysis of the SCS sandwich plates with ULCC and headed studs. The validations of the FEA against the test results showed that the FEM could simulate well the damage evolution in the steel materials.

(2) With the validated FEM, the ultimate strength behaviour of the SCS sandwich plate under different surface loading area were studied. The FE parametric studies showed that as the surface loading area ratio (loading area over area of the top surface) increased from 0.1 to 1.0 the failure mode changed from punching shear of the ULCC core to the connectorfailed type of flexure mode; the ultimate resistances of the SCS sandwich plate increased, but the surface loading pressure significantly decreased.

(3) With the FE predicted ultimate resistances of SCS sandwich plate under different surface loading area, it was observed that the ISO criteria with a reasonable safety factor could be satisfied for all the developed SCS sandwich plate type of ice-resisting wall. The comparisons of the resistances of the developed SCS sandwich plate with the ISO ice-contact pressure further confirms that the developed SCS sandwich plate system could be used to resist the ice-contact pressure in the Arctic offshore constructions.

\section{Acknowledgements}

The authors would like to acknowledge the research grant 51608358 received from National Natural Science Foundation of China for the works reported herein. The authors gratefully express their gratitude for these financial supports.

\section{Compliance with ethical standards:}

Funding: This study was funded by National Natural Science Foundation of China (grant number 51608358).

Conflict of Interest: The authors declare that they have no conflict of interest.

\section{Nomenclature}

\footnotetext{
$D_{c}=$ Compressive damage ratio of concrete

$D_{i}=$ Damage ratio of steel at load step i

$D_{t}=$ Tensile damage ratio of concrete

$D_{R}=$ Damage ratio of steel

$E_{0}=$ Initial elastic modulus of concrete

$E_{\mathrm{s}}=$ Elastic modulus of the steel

$E_{s h}=$ Elastic modulus of the headed stud

$P_{1}=$ First peak resistance in the load-deflection curves of the SCS sandwich plate

$P_{2}=$ Second peak resistance in the load-deflection curves of the SCS sandwich plate

$S_{a}=$ Spacing of the connectors in the SCS sandwich plate

$f_{c}=$ Compressive stress at the softening region in the stress-strain curve

$h_{c}=$ Thickness of the core material in SCS sandwich plate

$h_{t}=$ Depth of the composite section in SCS sandwich plate

$t_{c}=$ Thickness of the compressive steel face plate

$t_{t}=$ Thickness of the tensile steel face plate

$\delta_{f}=$ Central deflection of the shell

$\sigma_{c}=$ Uniaxial compressive stress of concrete

$\sigma_{t}=$ Uniaxial tensile stress of concrete

$\sigma_{c u}=$ Uniaxial ultimate compressive stress of concrete

$\sigma_{t 0}=$ Uniaxial ultimate tensile stress of concrete

$\delta_{f}=$ Uniaxial ultimate tensile stress of concrete

$v=$ Poisson's ratio
}

\section{Abbreviations}

$\mathrm{CDM}=$ continuum damage model;

$\mathrm{CDPM}=$ concrete damage plasticity model;

$\mathrm{COV}=$ coefficient of variation; $\mathrm{FE}=$ finite element;

$\mathrm{FEA}=$ finite element analysis;

$\mathrm{FEM}=$ finite element model;

HSS=headed shear stud connector.

\section{References}

[1] Marshall P.W., Sohel K.M.A., Liew J.Y.R., Yan J.B., Palmer A. and Choo Y.S, "Development of Steel-Concrete-Steel sandwich composite shell for Arctic Caissons", In: Offshore technology conference, paper no. 23818, Houston, Texas, USA; 3-5 December.

[2] Yan J.B., Liu X.M., Liew J.Y.R., Qian X. and Zhang, M.H., "Steel-concrete-steel sandwich system in Arctic offshore structure: Materials, experiments, and design. Materials \& Design, 91, 111-121, 2016.

[3] Yan J.B., Liew J.Y.R. and Zhang M.H., "Mechanical properties of normal strength mild steel and high strength steel S690 in low temperature relevant to Arctic environment”, Materials \& Design, 61, 150-159, 2014.

[4] Birdy J.N. and Bhula D.N., "Punching resistance of slabs and shells used for Arctic concrete platforms", Offshore Technology Conference, Paper No. 4855, 135-150. 5/6/1985, Houston, Texas. 1985.

[5] Croasdale K.R., "Ice interaction with structures: recent developments and future trends", Arctic Technology Conference, Calgary, Sept. 1985.

[6] Palmer A.C. and Croasdale K.R., "Arctic Offshore Engineering", World Scientific, 2012.

[7] Ellis R.M. and Macgregor J.G., "Tests on arch-shaped ice-resisting walls for offshore structures", ACI Structural Journal, 90(1), 42-51, 1993.

[8] Long T.P., "Experimental and analytical investigations on punching shear of thick, lightweight concrete plates and shells", PhD thesis, Washington University, 1988.

[9] Mclean D.I., "A study of punching shear strength of curved slabs", Ph.D. Thesis, Cornell University, USA. 1987

[10] McLean D.I., Phan L.T., Lew H.S. and White R.N., "Punching shear behavior of lightweight concrete slabs and shells", ACI structural Journal, 7(4), 386-392, 1990.

[11] Nojiri Y., Koseki K., Yoshiki T. and Sawayanagi M., "Structural behavior and design method of steel/concrete composite ice walls for Arctic offshore structures", Offshore Technology Conference, Paper No. 5292, 597-604, 1986.

[12] Shukry M.E.S. and Goode C.D., "Punching shear strength of composite construction", ACI Structural Journal, 87(1), 12-22, 1990.

[13] Yan J.B., Liew J.Y.R., Zhang M.H. and Li Z.X., "Punching shear resistance of steelconcrete-steel sandwich composite shell structure”, Engineering Structures, 117, 470-485, 2016 .

[14] Sohel K.M.A. and Liew J.Y.R., "Steel-Concrete-Steel sandwich slabs with lightweight coreStatic performance", Engineering Structures, 33(3), 981-992, 2011.

[15] Shanmugam N.E., Kumar G. and Thevendran V., "Finite element modeling of double skin composite slabs", Finite Elements in Analysis and Design, 38(7), 579-599, 2002.

[16] Yan J.B., Wang J.Y., Liew J.Y.R. and Qian, X., "Punching shear behavior of steel-concretesteel sandwich composite plate under patch loads", Journal of Constructional Steel Research, $121,50 \sim 64,2016$

[17] Yan J.B. and Liew J.Y.R., "Design and behavior of steel-concrete-steel sandwich plates subject to concentrated loads", Composite Structures, 150, 139-152, 2016.

[18] Yan J.B., Wang J.Y., Liew J.Y.R., Qian X.D. and Zong, L., "Ultimate strength behaviour of steel-concrete-steel sandwich plate under concentrated loads", Ocean Engineering, 118, 4157, 2016.

[19] Yan J.B., Wang J.Y., Liew J.Y.R. and Zhang, M.H., "Applications of ultra-lightweight cement composite in flat slabs and double skin composite structure", Construction and Building Materials, 111, 774-796, 2016.

[20] Foundoukos, N. and Chapman, J.C., "Finite element analysis of steel-concrete-steel sandwich beams", Journal of Constructional Steel Research, 64(9), 947-961, 2008.

[21] Yan J.B., Liew J.Y.R. and Zhang M.H., "Shear-tension interaction strength of J-hook connectors in steel-concrete-steel sandwich structure", Advanced Steel Construction, 11(1), 72-93, 2015.

[22] Sohel K.M.A., Liew J.Y.R. and Koh, C.G., "Numerical modelling of lightweight SteelConcrete-Steel sandwich composite beams subjected to impact", Thin-Walled Structures, 94(9), 135-146, 2015.

[23] Yan J.B., Qian, X., Liew J.Y.R. and Zong L., "Damage plasticity based numerical analysis on steel-concrete-steel sandwich shells used in the Arctic offshore structure", Engineering Structures, 117, 542-559, 2016.

[24] Yan J.B. and Zhang W., "Numerical analysis on steel-concrete-steel sandwich plates by damage plasticity model: From materials to structures", Construction and Building Materials, 149, 801-815, 2017.

[25] Chia K.S., Zhang M.H. and Liew J.Y.R., "High-strength ultra lightweight cement composite -material properties", Proceedings of the 9th international symposium on high performance concrete-design, verification \& ulitility, Rotorua, New Zealand, August, 2011.

[26] Yan J.B., Wang J.Y., Liew J.Y.R., Qian X. and Zhang, W., "Reinforced ultra-lightweight cement composite flat slabs: Experiments and analysis", Materials \& Design, 95, 148-158, 2016.

[27] Wang J.Y., Chia K.S., Liew J.Y.R. and Zhang M.H., "Flexural performance of fibrereinforced ultra-lightweight cement composites with low fibre content", Cement Concrete Composite, 43, 39-47, 2013.

[28] ABAQUS, "ABAQUS Standard User's Manual", Version 6.12. Providence, RI (USA): Dassault Systemes Corp; 2012

[29] Lubliner J., Oliver J., Oller S. and Oñate, E., "A plastic-damage model for concrete", International Journal of Solids and Structures, 25(3), 299-326, 1989.

[30] Lee J. and Fenves G.L., "Plastic-damage model for cyclic loading of concrete structures", Journal of Engineering Mechanics, ASCE, 124(8), 892-900, 1998.

[31] Wang J.C. and Chen Y.K., "Applications of ABAQUS in Civil Engineering (in Chinese)", Press of Zhejiang University, Publication No. C2118999F, China, 2006.

[32] Shanmugam N.E., Kumar G. and Thevendran V., "Finite element modeling of double skin composite slabs", Finite Elem Anal Des, 38(7), 579-99, 2002.

[33] International Standards Organization. ISO/FDIS 19906: 2010(E). Petroleum and natural gas industries - Arctic offshore structures; 2010. 